\title{
Population structure of Bathymodiolus manusensis, a deep- sea hydrothermal vent-dependent mussel from Manus Basin, Papua New Guinea
}

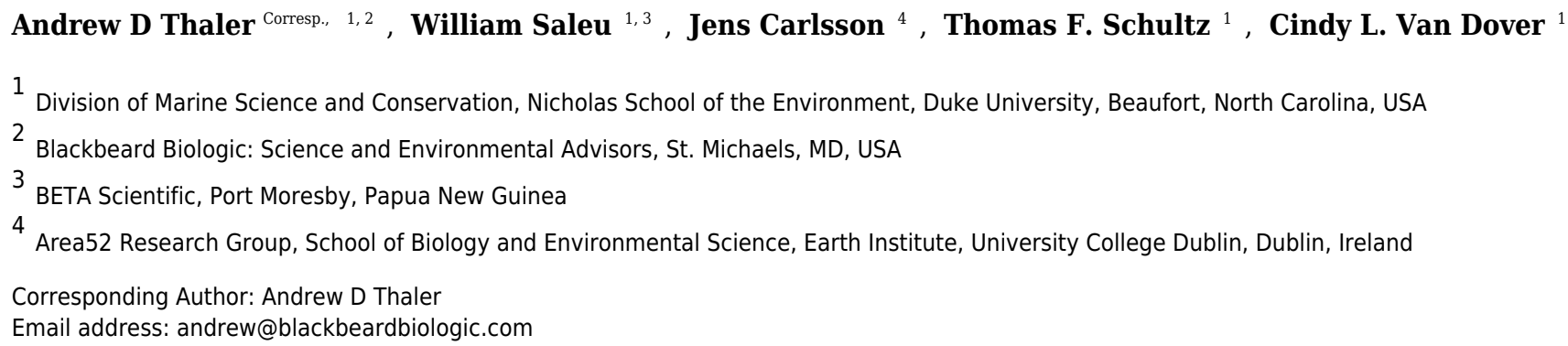

Deep-sea hydrothermal vents in the western Pacific are increasingly being assessed for their potential mineral wealth. To anticipate the potential impacts on biodiversity and connectivity among populations at these vents, environmental baselines need to be established. Bathymodiolus manusensis is a deep-sea mussel found in close association with hydrothermal vents in Manus Basin, Papua New Guinea. Using multiple genetic markers (cytochrome $C$-oxidase subunit-1 sequencing and 8 microsatellite markers), we examined population structure at two sites in Manus Basin separated by $40 \mathrm{~km}$ and near a potential mining prospect, where the species has not been observed. No population structure was detected in mussels sampled from these two sites. We also compared a subset of samples with $B$. manusensis from previous studies to infer broader population trends. The genetic diversity observed can be used as a baseline against which changes in genetic diversity within the population may be assessed following the proposed mining event. 
1

2 Population structure of Bathymodiolus manusensis, a deep-sea hydrothermal-vent-dependent

3 mussel from Manus Basin, Papua New Guinea

4 Andrew David Thaler ${ }^{1,2, *}$, William Saleu ${ }^{1,3}$, Jens Carlsson ${ }^{4}$, Thomas F. Schultz ${ }^{1}$, Cindy Lee Van

5 Dover $^{1}$

6

$7{ }^{1}$ Division of Marine Science and Conservation, Nicholas School of the Environment, Duke

8 University, Beaufort NC, USA

$9{ }^{2}$ Current affiliation: Blackbeard Biologic: Science and Environmental Advisors, St. Michaels, 10 MD, USA

$11{ }^{3}$ Current affiliation: BETA Scientific, Port Moresby, Papua New Guinea.

$12{ }^{4}$ Area52 Research Group, School of Biology and Environmental Science, Earth Institute, 13 University College Dublin, Dublin, Ireland

14 *Corresponding Author: andrew@blackbeardbiologic.com

\section{Abstract}

Deep-sea hydrothermal vents in the western Pacific are increasingly being assessed for their potential mineral wealth. To anticipate the potential impacts on biodiversity and connectivity among populations at these vents, environmental baselines need to be established. Bathymodiolus manusensis is a deep-sea mussel found in close association with hydrothermal vents in Manus Basin, Papua New Guinea. Using multiple genetic markers (cytochrome Coxidase subunit-1 sequencing and 8 microsatellite markers), we examined population structure at two sites in Manus Basin separated by $40 \mathrm{~km}$ and near a potential mining prospect, where the species has not been observed. No population structure was detected in mussels sampled from these two sites. We also compared a subset of samples with B. manusensis from previous studies to infer broader population trends. The genetic diversity observed can be used as a baseline against which changes in genetic diversity within the population may be assessed following the

28 proposed mining event. 


\section{Introduction}

Hydrothermal vents support large, endemic communities fueled by chemoautotrophic primary production (Gage \& Tyler, 1991; Van Dover, 2000), in contrast to the relatively lowbiomass found on the deep seafloor. In Southwest Pacific back-arc basins, active vents are patchily distributed and subject to local disturbances, including the waxing and waning of hydrothermal flow on short time scales and cessation of flow on millennial timescales (Van Dover, 2000; Vrijenhoek, 2010). Species demographics may be driven as much by stochastic processes related to disturbance as by response to changing environmental conditions or other ecological phenomena (Vrijenhoek, 2010; Thaler et al., 2014). In general, hydrothermal vent communities are thought to be more resilient to disturbance compared to other deep-sea ecosystems (Van Dover, 2014).

Deep-sea hydrothermal vents are increasingly being explored for potential mineral extraction (Van Dover, 2010). Almost 20\% of all known global vent fields currently fall within mining exploration leases (Beaulieu et al., 2013). Establishing baselines for the diversity and connectivity of vent systems is a necessary first step in effective environmental management regimes (Collins et al., 2013). As vents become targets for mineral extraction, managers will need to assess regional biodiversity and connectivity and potential cumulative impacts of multiple mining events in a region (Boschen et al. 2013, Van Dover 2014) and design refugia to mitigate the impacts of mining on the vent ecosystem (Collins, Kennedy \& Van Dover, 2012). Bathymodiolus manusensis is a deep-sea mussel found at hydrothermal vents in the Manus Basin, Papua New Guinea. It commonly occurs around low-temperature diffuse-flow vent sites on the periphery of active hydrothermal chimneys (Hashimoto \& Furuta, 2007). Though B. manusensis shares close affinity with other bathymodiolin mussels in Lau and North 
52 Fiji Basins (B. brevior), B. manusensis is primarily found within Manus Basin (Hashimoto \&

53 Furuta, 2007; Kyuno \& Shintaku, 2009) and has been reported from a few sites in Lau Basin

54 (Miyazaki et al., 2004), as well as off the coast of New Zealand (Miyazaki et al., 2010). B.

55 manusensis is one of several habitat-forming mollusks that host chemoautotrophic

56 endosymbionts and derive chemical energy from hydrothermal vent effluent in Manus Basin

57 (Galkin, 1997). While other endosymbiont-hosting species at Manus Basin vents, such as

58 Ifremeria nautilei and Alviniconcha spp. (Bouchet \& Waren, 1991; Kojima et al., 2001; Urakawa

59 et al., 2005), tend to cluster around orifices where vent effluent is most concentrated, $B$.

60 manusensis occupies the periphery of high temperature hydrothermal ecosystems, taking

61 advantage of the less space-restrictive regions around diffuse flow sites (Kyuno \& Shintaku,

62 2009).

The Solwara 1 vent site in Manus Basin is licensed for extraction of metals associated with seafloor massive sulfides (Coffey Natural Systems, 2008). While B. manusensis does not occur at Solwara 1, it is abundant at the neighboring Solwara 8 site (40 km distant) and at the proposed set-aside, South Su (2.5 km distant; (Coffey Natural Systems, 2008)). Previous studies of connectivity in invertebrate taxa at these sites reveal species-specific patterns of connectivity among sites. Ifremeria nautilei and Chorocaris sp. 2, two endosymbiont-hosting vent species show no signs of genetic differentiation among Solwara1, Solwara 8, and South Su (Thaler et al. 2011; Thaler et al. 2014) while significant local differentiation was detected in the ventassociated Munidopsis lauensis (Thaler et al. 2014). B. manusensis has a limited geographic range and is not ubiquitous at active vents in Manus Basin, leading us to anticipate that it might exhibit local-scale genetic differentiation. Because B. manusensis is absent from Solwara 1 and because Solwara 1 is situated between Solwara 8 and South $\mathrm{Su}$, we tested the hypothesis that 
75 populations from South Su and Solwara 8 are isolated from each other, forming two genetically 76 distinct populations.

77

78 
81

82

83

84

\section{Materials and Methods}

\section{Sample collection and DNA extraction}

As part of a larger study looking at multi-species biodiversity and population structure within Manus Basin, Bathymodiolus manusensis were collected from two hydrothermal vent sites (Solwara 8 and South Su; Figure 1) during the $M / V$ Nor Sky research campaign (June-July 2008; Chief Scientist: S. Smith) using an ST200 ROV modified for biological sampling. For COI analyses, B. manusensis were analyzed from two discrete sulfide mounds at each site (Table 1), with 10 to 43 individuals per mound (Table 2). For microsatellite analyses, up to 142 individuals per locus were analyzed. All sampling was undertaken with the permission of the government of Papua New Guinea and did not involve endangered or protected species.

Mantle tissue was dissected from each individual and preserved in $95 \%$ ethanol prior to DNA extraction. Genomic DNA was isolated using a standard Chelex-Proteinase-K extraction (10-30 mg tissue digested with $120 \mu \mathrm{g}$ Proteinase K (Bioline: Taunton, MA) in $600 \mu 1$ 10\% Chelex-100 resin (Bio-Rad: Hercules, CA) overnight at $60^{\circ} \mathrm{C}$, heated to $100^{\circ} \mathrm{C}$ for $15 \mathrm{~min}$, and centrifuged at 10,000 rpm for 5 minutes; (Walsh, Metzger \& Higuchi, 1991). Extracted DNA was stored at $4^{\circ} \mathrm{C}$ until amplification and archived at $-20^{\circ} \mathrm{C}$.

\section{COI sequencing and analysis}

Bathymodiolus manusensis mitochondrial COI fragments were amplified using the following reaction conditions: 10 to $100 \mathrm{ng}$ of DNA template was combined with $2 \mu \mathrm{L} 10 \mathrm{x}$ PCR buffer (200 mM Tris, pH 8.8; $500 \mathrm{mM} \mathrm{KCl;} \mathrm{0.1 \%} \mathrm{Triton} \mathrm{X-100;} 0.2 \mathrm{mg} / \mathrm{ml} \mathrm{BSA}$ ), $2 \mathrm{mM} \mathrm{MgCl}$, $0.2 \mathrm{mM}$ dNTPs, $0.5 \mu \mathrm{M}$ LCOI1490 and $0.5 \mu \mathrm{M}$ HCOI2198 primers (Folmer et al., 1994), and 1 unit of Taq polymerase in a $20 \mu \mathrm{L}$ reaction with the following PCR protocol: initial melting 
104 temperature of $94^{\circ} \mathrm{C}$ for 240 seconds; 35 cycles of $94^{\circ} \mathrm{C}$ for 15 seconds, $48^{\circ} \mathrm{C}$ for 15 seconds,

$10572^{\circ} \mathrm{C}$ for 30 seconds; and a final extension of $72^{\circ} \mathrm{C}$ for 300 seconds. Products were stored at $4{ }^{\circ} \mathrm{C}$ 106 until purification.

$107 \quad$ Fourteen $\mu \mathrm{l}$ of PCR product was incubated with $0.2 \mu 110 \mathrm{X}$ ExoAP buffer (500 mM Bis-

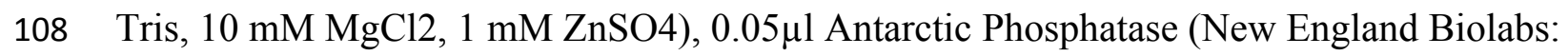

109 Ipswich, MA), $0.05 \mu 1$ Exonuclease I (New England Biolabs: Ipswich, MA) at $37^{\circ} \mathrm{C}$ for $60 \mathrm{~min}$ 110 followed by $85^{\circ} \mathrm{C}$ for $15 \mathrm{~min}$ to remove unincorporated nucleotides. Sequencing reactions were 111 executed with BigDye Terminator v3 reactions (Applied Biosystems: Foster City, CA). AMPure 112 magnetic beads (Agencourt: Morrisville, NC) were used to remove excess dye, products were 113 analyzed on an ABI 3730xl DNA Analyzer (Applied Biosystems International), and 114 chromatograms were edited using CodonCode Aligner (version 3.7.1; CodonCode Corporation: 115 Dedham, MA). Consensus sequences were compared against the NCBI GenBank database to 116 confirm identity when available (Benson, 1997) and sequence alignments were constructed using 117 the MUSCLE alignment algorithm (Edgar, 2004) implemented in CodonCode Aligner.

118 Representative sequences of dominant haplotypes were deposited in GenBank (Accession \# 119 KF498731 - KF498847). Full COI sequences for each individual are provided as FASTA files 120 (Supplemental File 1).

121 Standard summary statistics, including number of haplotypes $(H)$, haplotype diversity $122(H d)$, nucleotide diversity $(\pi)$, and Fu's $F_{S}$ were calculated using DnaSP version 5.10.01 123 (Librado \& Rozas, 2009). To detect potential cryptic species, maximum-parsimony phylograms 124 of aligned mitochondrial sequences were assembled in MEGA version 5 (10,000 replicates; 125 Tamura 3-parameter substitution model determined by Mega 5: Find Best-Fit Substitution 126 Model; Tamura et al. 2011). To visualize potential population structure, statistical-parsimony 
127 networks were assembled in TCS version 1.21 (default settings; Clement et al. 2000). To detect 128 population structure, Arlequin version 3.5.1.2 (Excoffier, Laval \& Schneider, 2005) was used to 129 estimate pairwise $\varphi_{S T}$. Sequential Bonferroni was used in all appropriate comparisons to correct 130 for multiple tests (Rice, 1989). Additional Bathymodiolus manusensis samples were identified in NCBI GenBank

132 133

134 135

(Accession Numbers KU597590.1 through KU597592.1 from PACMANUS in Manus Basin (Assié et al., 2016); AB101431.1 through AB101434.1 from PACMANUS in Manus Basin (Miyazaki et al., 2004); AB257539.1, AB257541.1, and AB257543.1 from Lau Basin (Miyazaki et al., 2010); and AB255739.1, AB255740.1, AB255741.1, and AB255742.1 from offshore New Zealand (Miyazaki et al., 2010)). A Neighbor-Joining tree (10,000 bootstrap replicates) was assembled from 3 sequenced individuals from Solwara 8, 3 individuals from South Su, as well as 7 individuals from PACMANUS, 3 individuals from Lau Basin, and 4 individuals from offshore New Zealand GenBank sequences using MEGA 7 (Kumar, Stecher \& Tamura, 2016).

\section{Microsatellite genotyping and statistical analyses}

Eight microsatellite markers (Bm17, Bm22, Bm23, Bm53, Bm63, Bm76, Bm81, Bm83)

were amplified from Bathymodiolus manusensis in Manus Basin following methods reported in (Schultz et al., 2010). To test whether these markers provided sufficient power to evaluate the null hypothesis of genetic homogeneity, models of the dataset were implemented in POWSIM (Settings based on observed allele distributions, Supplement 1; Ryman and Palm, 2006). Full microsatellite genotypes for each individual are provided as GENPOP files (Supplemental File 2). 
Equilibrium (HWE) and allelic richness were assessed using GENEPOP (default settings;

151

152

153

154

155

156

157

158

159

160

161

162

163

164

165

166

version 4.0; Rousset 2008) and Microsatellite Analyzer (version 4.05; Dieringer \& Schlötterer

2003), respectively. Permutation tests were used to determine significant variation in allelic

richness (F-stat; default settings; version 2.9.3.2; Goudet 1995). MicroChecker (version 2.2.3;

1000 randomizations; van Oosterhout et al. 2004) was used to detect the potential presence of

null alleles, stutter, and large allele dropout. To test for the potential influence of selection, loci

were screened using LOSITAN (25,000 simulations; IA and SMM; Antao et al. 2008; Beaumont \& Nichols 1996).

Pairwise genetic differentiation $\left(F_{S T}\right)$ between aggregations, sites, and basins was analyzed using Microsatellite Analyzer. Alpha levels were adjusted via Sequential Bonferroni to correct for multiple tests (Rice, 1989). Structure version 2.3.3 (admixture model, sampling locations as prior distributions; Pritchard et al. 2000) was used to visualize potential population structure. Analyses were conducted with a 1,000,000 step burn-in, 10,000,000 repetitions, and 3 replicates per level from $\mathrm{K}=1$ to 7 . Effective population size was estimated based on microsatellite linkage-disequilibrium using LDNe (default parameters; Waples \& Do 2008). 


\section{Results}

Of 20 COI haplotypes (409 bp) identified, 5 were shared at both sites, 3 were only found

in Solwara 8 samples, and 13 were only found at South Su. Bathymodiolus manusensis from Solwara 8 (47 individuals) and South Su (53 individuals) in Manus Basin (Table 2) comprised a single haplogroup, based on $C O I$ analysis. A maximum of 5 base-pair mutations separated the most divergent haplotypes (Table 2, Figure 2). The statistical parsimony network for $B$. manusensis has a wheel-and-spoke topology, with a single central dominant haplotype and numerous low-abundance secondary haplotypes (Figure 2). The dominant haplotype is roughly evenly distributed among both sites and all relatively abundant haplotypes $(\mathrm{n} \geq 3)$ occur at both Solwara 8 and South $\mathrm{Su}$ (Figure 2). Fu's $F_{S}$ values for $C O I$ sequence data were significantly negative for samples pooled from both sites, as well as within sites and at Mound 1 (Solwara 8) and Mound 4 (South Su; Table 2).

Neighbor-joining phylogenetic analysis of a 370-base pair COI segment shared among Bathymodiolus manusensis from neighboring sites and basins indicated low variability across sites, with samples from within Manus Basin being closely related to each other, while samples from Lau Basin and offshore New Zealand were basal to all Manus Basin samples (Supplemental Figure 1).

\section{Eight microsatellite loci were amplified from Bathymodiolus manusensis (35 to 142} individuals per site; Table 3$)$. Alleles per locus ranged from 3 to $20($ mean $=10)$. Allelic richness $(R s)$ did not vary significantly among mounds or sites $(10,000$ permutations, $P>0.05$; Table 3$)$ and neither balancing nor directional selection was detected at any spatial scale (LOSITAN, P > 0.05). Only one marker deviated from Hardy-Weinberg expectations and showed evidence for heterozygote deficiency at Solwara (Bm53; Table 3). POWSIM indicated that the sample set has sufficient statistical power to accept or reject the null hypothesis of genetic homogeneity. 
191 MicroChecker indicated that null alleles were present at that loci and were responsible for

192 heterozygote deficiencies. As the presence of null alleles has been shown not to severely bias

193 assignment tests (Carlsson, 2008), this marker was included in subsequent analyses.

194 Analysis of Molecular Variance (AMOVA) and pairwise tests for population

195 differentiation $\left(F_{S T}\right.$ and $\left.\varphi_{S T}\right)$ based on $C O I$ sequences and microsatellite markers indicated no

196 significant genetic differentiation among Bathymodiolus manusensis from Solwara 8 and South

197 Su (Table 4). Assignment tests for combined COI and microsatellite data placed all $B$.

198 manusensis into a single population (Structure, $\mathrm{K}=1$, data not shown). Effective population size

199 estimated from microsatellite linkage disequilibrium (LDNe) was functionally infinite.

200

201 
202

203

204

205

206

207

208

209

210

211

212

213

214

215

216

217

218

219

220

221

222

223

\section{Discussion}

\section{Population structure of Bathymodiolus manusensis in Manus Basin}

Bathymodiolus manusensis form a single, coherent population between Solwara 8 and South Su in Manus Basin, Papua New Guinea. No genetic differentiation was detected at any spatial scale using either mitochondrial COI or nuclear microsatellite markers. Despite this apparent lack of population structure, B. manusensis is absent from Solwara 1, a site that occurs between Solwara 8 and South Su and that is within 2.5 kilometers of South Su. Further, Solwara 1 shares many vent-dependent and vent-associated species with Solwara 8 and South Su (Coffey Natural Systems, 2008; Erickson, Macko \& Van Dover, 2009; Thaler et al., 2011, 2014; Plouviez et al., 2013).

The relatively homogeneous distribution of both COI haplotype and microsatellite markers for Bathymodiolus manusensis within Manus Basin is consistent with high gene flow between Solwara 8 and South Su. Similar levels of gene flow were observed in Ifremeria nautilei (Thaler et al. 2011) and Chorocaris sp. 2 (Thaler et al. 2014), although in both cases, the species were also found at Solwara 1. A significant, negative Fu's $\mathrm{F}_{\mathrm{S}}$ is consistent with a recent, rapid expansion, a pattern also observed in other species examined from these sites (Thaler et al. 2011, Plouviez et al. 2013, Thaler et al. 2014). COI haplotype diversity is higher at South Su (0.59 compared to Solwara 8's 0.45 ; Table 2), however, there is no consistent pattern of microsatellite richness between the two sites, nor are unique alleles consistently identified at one site over the other. A potential alternate explanation could be that both sites were recently colonized by the same cohort, and though currently isolated, have not had enough time for significant differentiation to accumulate via genetic drift. 
least 4 research campaigns, neither Bathymodiolus manusensis nor any other mussel in the genus

the seafloor suggest that adequate substrate (hard basalt surrounding low temperature venting observation), although the fluid chemistry that might influence mussel recruitment has not been characterized for Manus vents. In a previous study, we identified a similar pattern of presence/absence among populations of Munidopsis lauensis at Solwara 8 and South Su (Thaler et al., 2014). One population of M. lauensis was found at Solwara 8 and South Su, but absent at Solwara 1, while a second population was restricted to samples from Solwara 1 (Thaler et al., 2014). We hypothesized that sweepstakes effects related to the survival and settlement of recruits at vent sites in Manus Basin was responsible for the observed population structure of M. lauensis and that time series sampling would reveal a stochastic, dynamic distribution of these populations throughout the basin (Thaler et al., 2014).

When compared with putative Bathymodiolus manusensis samples from other sites in

Manus Basin as well as Lau Basin and offshore New Zealand, there is a similarly high affinity between Solwara 8, South Su, and PACMANUS samples, suggesting a larger, well-mixed surrounding regions, and that there is a greater retention of propagules within Manus Basin, resulting in less gene flow and increased isolation within Manus Basin. Similar patterns of isolation within Manus Basin were observed in Ifremeria nautilei and Chorocaris sp. 2 (Thaler et al., 2011, 2014). 

population of Munidopsis lauensis suggests that the apparent exclusion of certain species or populations from Solwara 1 may be the result of a consistent, species- and population-dependent, dispersal barrier, rather than stochastic recruitment events. Other "leaky" dispersal barriers have barrier restricting some, but not all, species (or populations) from recruiting to Solwara 1, we need to sample additional species to identify consistent patterns across multiple taxa and sample the same species at additional time points to establish if observed patterns are temporally stable. The alternative hypothesis that species and populations are adapted to particular environmental conditions that are not always present at a site remains plausible (and not mutually exclusive), especially given well-documented evidence for such circumstances in Alviniconcha species in Lau Basin (Beinart et al. 2012) and the lack of fluid chemistry data from evident and putative mussel habitats at Manus Basin vents.

\section{Implications for management strategies} availability within vent ecosystems and the value of comprehensive environmental baselines

267 prior to the initiation of an extractive regime (Collins, Kennedy \& Van Dover, 2012; Collins et 
270 regime shifts in vent communities of Manus Basin as has been noted in other marine ecosystems

271 (Scheffer \& Carpenter, 2003). A similar phenomenon was observed in Moorea coral reef

272 communities, where persistent disturbance, caused, in this case, by invasive crown-of-thorn

273 starfish resulted in permanent changes in community structure as opportunistic recruits occupied

274 newly exposed ecologic niches (Berumen \& Pratchett, 2006).

275 The potential for regime shifts, where species not present at the disturbance site but

276 occurring at neighboring sites establish a foothold following anthropogenic impacts, creates a

277 challenge for environmental management and mitigation programs. At the very least, there is a

278 need to understand if such a regime shift constitutes a significant adverse impact that should

279 trigger a management response. Managers need to understand the extent of local variation in

280 population and community structure to anticipate cumulative impacts and ecological

281 consequences of regime changes following disturbance. 


\section{Acknowledgements}

284 We thank Dr. Samantha Smith and Renee Grogan of Nautilus Minerals, the captain and crew of 285 the M/V Nor Sky, the Canyon Offshore ROV team, and Rebecca Jones and Pen-Yuan Hsing for 286 assistance with field sampling. We thank Bernard Ball for laboratory assistance and Clifford

287 Cunningham for advice and consultation. Specimens of Bathymodiolus manusensis from Manus 288 Basin collected for this work are the property of Papua New Guinea, held in trust by Nautilus 289 Minerals, and loaned to Duke University for baseline studies for the Solwara 1 Project. We thank 290 two anonymous reviewers for their comments and critiques. 
291

292

293

294

295

296

297

298

299

300

301

302

303

304

305

306

307

308

309

310

311

312

313

314

315

316

317

318

319

320

321

322

323

324

325

326

327

328

329

330

331

\section{References}

Antao T., Lopes A., Lopes R., Beja-Pereira A., Luikart G. 2008. LOSITAN: a workbench to detect molecular adaptation based on a Fst-outlier method. BMC Bioinformatics 9:323.

Assié A., Borowski C., van der Heijden K., Raggi L., Geier B., Leisch N., Schimak MP., Dubilier N., Petersen JM. 2016. A specific and widespread association between deep-sea Bathymodiolus mussels and a novel family of Epsilonproteobacteria. Environmental Microbiology Reports 8:805-813. DOI: 10.1111/1758-2229.12442.

Beaulieu SE., Baker ET., German CR., Maffei A. 2013. An authoritative global database for active submarine hydrothermal vent fields. Geochemistry, Geophysics, Geosystems 14:4892-4905. DOI: 10.1002/2013GC004998.

Beaumont MA., Nichols RA. 1996. Evaluating Loci for Use in the Genetic Analysis of Population Structure. Proceedings of the Royal Society B: Biological Sciences 263:16191626. DOI: $10.1098 / \mathrm{rspb} .1996 .0237$.

Benson D. 1997. GenBank. Nucleic Acids Research 25:1-6. DOI: 10.1093/nar/25.1.1.

Berumen ML., Pratchett MS. 2006. Recovery without resilience: persistent disturbance and longterm shifts in the structure of fish and coral communities at Tiahura Reef, Moorea. Coral Reefs 25:647-653. DOI: 10.1007/s00338-006-0145-2.

Boschen RE., Collins PC., Tunnicliffe V., Carlsson J., Gardner JPA., Lowe J., McCrone A., Metaxas A., Sinniger F., Swaddling A. 2016. A primer for use of genetic tools in selecting and testing the suitability of set-aside sites protected from deep-sea seafloor massive sulfide mining activities. Ocean \& Coastal Management 122:37-48. DOI: 10.1016/j.ocecoaman.2016.01.007.

Bouchet P., Waren A. 1991. Ifremeria-nautilei, a new gastropod from hydrothermal vents, probably associated with symbiotic bacteria. CR Acad Sci Paris Ser III 312:495-501.

Carlsson J. 2008. Effects of microsatellite null alleles on assignment testing. The Journal of Heredity 99:616-23. DOI: 10.1093/jhered/esn048.

Clement M., Posada D., Crandall KA. 2000. TCS: a computer program to estimate gene genealogies. Molecular Ecology 4:331-346.

Coffey Natural Systems. 2008. Environmental Impact Statement: Nautilus Minerals Niugini Limited, Solwara 1 Project. Queensland, Australia.

Collins P., Kennedy B., Copley J., Boschen R., Fleming N., Forde J., Ju S-J., Lindsay D., Marsh L., Nye V., Patterson A., Watanabe H., Yamamoto H., Carlsson J., David Thaler A. 2013. VentBase: Developing a consensus among stakeholders in the deep-sea regarding environmental impact assessment for deep-sea mining-A workshop report. Marine Policy 42:334-336. DOI: 10.1016/j.marpol.2013.03.002.

Collins P., Kennedy R., Van Dover C. 2012. A biological survey method applied to seafloor massive sulphides (SMS) with contagiously distributed hydrothermal-vent fauna. Marine Ecology Progress Series 452:89-107.

Dieringer D., Schlötterer C. 2003. Microsatellite analyser (MSA): a platform independent analysis tool for large microsatellite data sets. Molecular Ecology Notes 3:167-169.

Van Dover CL. 2000. The Ecology of Deep-Sea Hydrothermal Vents. Princeton: Princeton 
332

333

334

335

336

337

338

339

340

341

342

343

344

345

346

347

348

349

350

351

352

353

354

355

356

357

358

359

360

361

362

363

364

365

366

367

368

369

370

371

372

University Press.

Van Dover CL. 2010. Mining seafloor massive sulphides and biodiversity: what is at risk? ICES Journal of Marine Science 68:341-348. DOI: 10.1093/icesjms/fsq086.

Van Dover CL. 2014. Impacts of anthropogenic disturbances at deep-sea hydrothermal vent ecosystems: a review. Marine environmental research 102:59-72. DOI: 10.1016/j.marenvres.2014.03.008.

Edgar R. 2004. MUSCLE: a multiple sequence alignment method with reduced time and space complexity. BMC Bioinformatics 5:113.

Erickson KL., Macko S., Van Dover CL. 2009. Evidence for a chemoautotrophically based food web at inactive hydrothermal vents (Manus Basin). Deep Sea Research Part II: Topical Studies in Oceanography 56:1577-1585. DOI: 10.1016/j.dsr2.2009.05.002.

Excoffier L., Laval G., Schneider S. 2005. Arlequin ver. 3.0: an integrated software package for population genetics data analysis. Evolutionary Bioinformatics Online 1:47-50.

Felsenstein J. 1985. Confidence Limits on Phylogenies: An Approach Using the Bootstrap. Evolution 39:783. DOI: 10.2307/2408678.

Folmer O., Black M., Hoeh W., Lutz R., Vrijenhoek R. 1994. DNA primers for amplification of mitochondrial cytochrome $\mathrm{c}$ oxidase subunit I from diverse metazoan invertebrates. Molecular Marine Biology and Biotechnology 3:294-299.

Gage JD., Tyler PA. 1991. Deep-Sea Biology: A Natural History of Organisms at the Deep-Sea Floor. Cambridge University Press.

Galkin SV. 1997. Megafauna associated with hydrothermal vents in the Manus Back-Arc Basin (Bismarck Sea). Marine geology 142:197-206. DOI: 10.1016/S0025-3227(97)00051-0.

Goudet J. 1995. FSTAT version 1.2: a computer program to calculate F-statistics. Journal of Heredity 86:485-486.

Hashimoto J., Furuta M. 2007. A New Species of Bathymodiolus (Bivalvia: Mytilidae) from Hydrothermal Vent Communities in the Manus Basin, Papua New Guinea. Venus: Journal of the Malacological Society of Japan 66:57-68.

Kojima S., Segawa R., Fijiwara Y., Fujikura K., Ohta S., Hashimoto J. 2001. Phylogeny of Hydrothermal-Vent - Endemic Gastropods Alviniconcha spp . from the Western Pacific Revealed by Mitochondrial DNA Sequences. The Biological Bulletin 200:298-304.

Kumar S., Stecher G., Tamura K. 2016. MEGA7: Molecular Evolutionary Genetics Analysis Version 7.0 for Bigger Datasets. Molecular Biology and Evolution 33:1870-1874. DOI: $10.1093 / \mathrm{molbev} / \mathrm{msw} 054$.

Kyuno A., Shintaku M. 2009. Dispersal and differentiation of deep-sea mussels of the genus Bathymodiolus (Mytilidae, Bathymodiolinae). Journal of Marine ... 2009:1-15. DOI: $10.1155 / 2009 / 625672$.

Librado P., Rozas J. 2009. DnaSP v5: a software for comprehensive analysis of DNA polymorphism data. Bioinformatics 25:1451-2. DOI: 10.1093/bioinformatics/btp187.

Miyazaki J-I., Martins L de O., Fujita Y., Matsumoto H., Fujiwara Y. 2010. Evolutionary Process of Deep-Sea Bathymodiolus Mussels. PLoS ONE 5:e10363. DOI: 10.1371/journal.pone.0010363. 
400

401

402

403

404

405

406

407

408

409

410

411

412

413

Miyazaki J-I., Shintaku M., Kyuno A., Fujiwara Y., Hashimoto J., Iwasaki H. 2004. Phylogenetic relationships of deep-sea mussels of the genus Bathymodiolus (Bivalvia: Mytilidae). Marine Biology 144:527-535. DOI: 10.1007/s00227-003-1208-3.

van Oosterhout C., Hutchinson WF., Wills DPM., Shipley P. 2004. micro-checker: software for identifying and correcting genotyping errors in microsatellite data. Molecular Ecology Notes 4:535-538. DOI: 10.1111/j.1471-8286.2004.00684.x.

Plouviez S., Le Guen D., Lecompte O., Lallier FH., Jollivet D. 2010. Determining gene flow and the influence of selection across the equatorial barrier of the East Pacific Rise in the tubedwelling polychaete Alvinella pompejana. BMC Evolutionary Biology 10:220. DOI: 10.1186/1471-2148-10-220.

Plouviez S., Schultz TF., McGinnis G., Minshall H., Rudder M., Van Dover CL. 2013. Genetic diversity of hydrothermal-vent barnacles in Manus Basin. Deep Sea Research Part I: Oceanographic Research Papers 82:73-79. DOI: 10.1016/j.dsr.2013.08.004.

Plouviez S., Shank TM., Faure B., Daguin-Thiebaut C., Viard F., Lallier FH., Jollivet D. 2009. Comparative phylogeography among hydrothermal vent species along the East Pacific Rise reveals vicariant processes and population expansion in the South. Molecular ecology 18:3903-17. DOI: 10.1111/j.1365-294X.2009.04325.x.

Pritchard J., Stephens M., Donnelly P. 2000. Inference of Population Structure Using Multilocus Genotype Data. Genetics 155:945-959.

Rice W. 1989. Analyzing tables of statistical test. Evolution 43:223-225.

Rousset F. 2008. Genepop'007: a complete reimplementation of the Genepop software for Windows and Linux. Molecular Ecology Resources 8:103-106.

Saitou N., Nei M. 1987. The neighbor-joining method: a new method for reconstructing phylogenetic trees. Molecular Biology and Evolution 4:406-425. DOI: 10.1093/oxfordjournals.molbev.a040454.

Scheffer M., Carpenter SR. 2003. Catastrophic regime shifts in ecosystems: linking theory to observation. Trends in Ecology \& Evolution 18:648-656. DOI: 10.1016/j.tree.2003.09.002.

Schultz T., Hsing P., Eng A., Zelnio K. 2010. Characterization of 18 polymorphic microsatellite loci from Bathymodiolus manusensis (Bivalvia, Mytilidae) from deep-sea hydrothermal vents. Conservation Genetics:8-10. DOI: 10.1007/s12686-010-9272-8.

Tamura K., Nei M., Kumar S. 2004. Prospects for inferring very large phylogenies by using the neighbor-joining method. Proceedings of the National Academy of Sciences 101:1103011035. DOI: $10.1073 /$ pnas.0404206101.

Tamura K., Peterson D., Peterson N., Stecher G., Nei M., Kumar S. 2011. MEGA5: Molecular Evolutionary Genetics Analysis using Maximum Likelihood, Evolutionary Distance, and Maximum Parsimony Methods. Molecular Biology and Evolution 28:2731-2739. DOI: 10.1093/molbev/msr121.

Thaler AD., Plouviez S., Saleu W., Alei F., Jacobson A., Boyle EA., Schultz TF., Carlsson J., Van Dover CL. 2014. Comparative population structure of two deep-sea hydrothermal-ventassociated decapods (Chorocaris sp. 2 and Munidopsis lauensis) from southwestern Pacific back-arc basins. PloS one 9:e101345. DOI: 10.1371/journal.pone.0101345. 
414 Thaler AD., Zelnio K., Saleu W., Schultz TF., Carlsson J., Cunningham C., Vrijenhoek RC., Van

415

416

417

418

419

420

421

422

423

424

425

426

427

428

429

430

431
Dover CL. 2011. The spatial scale of genetic subdivision in populations of Ifremeria nautilei, a hydrothermal-vent gastropod from the southwest Pacific. BMC Evolutionary Biology 11:372. DOI: 10.1186/1471-2148-11-372.

Urakawa H., Dubilier N., Fujiwara Y., Cunningham DE., Kojima S., Stahl D a. 2005. Hydrothermal vent gastropods from the same family (Provannidae) harbour epsilon- and gamma-proteobacterial endosymbionts. Environmental Microbiology 7:750-4. DOI: 10.1111/j.1462-2920.2005.00753.x.

Vrijenhoek RC. 2010. Genetic diversity and connectivity of deep sea hydrothermal vent metapopulations. Molecular Ecology 19:4391-411. DOI: 10.1111/j.1365294X.2010.04789.x.

Walsh PS., Metzger DA., Higuchi R. 1991. Chelex 100 as a medium for simple extraction of DNA for PCR-based typing from forensic material. BioTechniques 10:506-13.

Waples RS., Do C. 2008. Ldne: a Program for Estimating Effective Population Size From Data on Linkage Disequilibrium. Molecular ecology resources 8:753-6. DOI: 10.1111/j.17550998.2007.02061.x. 
432 Tables

433 Table 1. Bathymodiolus manusensis sampling locations in Manus Basin.

434

\begin{tabular}{ccccc}
\hline Site & Mound & Latitude & Longitude & Depth (m) \\
\hline Solwara 8 & Mound 1 & $3^{\circ} 43.740^{\prime} \mathrm{S}$ & $151^{\circ} 40.404^{\prime} \mathrm{E}$ & 1720 \\
& Mound 2 & $3^{\circ} 43.824^{\prime} \mathrm{S}$ & $151^{\circ} 40.458^{\prime} \mathrm{E}$ & 1710 \\
South Su & Mound 3 & $3^{\circ} 48.564^{\prime} \mathrm{S}$ & $152^{\circ} 6.144^{\prime} \mathrm{E}$ & 1300 \\
& Mound 4 & $3^{\circ} 48.492^{\prime} \mathrm{S}$ & $152^{\circ} 6.186^{\prime} \mathrm{E}$ & 1350 \\
\hline
\end{tabular}

435

436 
437 Table 2. Bathymodiolus manusensis. Summary statistics for COI sequences (409 bp) from

438 Manus Basin. N: number of individuals, $\mathrm{H}$ : number of haplotypes, $H d$ : haplotype diversity, $F_{S}$ :

439 Fu's $F_{S}$. Significant Fu's $F_{S}$ indicated in bold.

440

\begin{tabular}{lrrrr}
\hline Location & $\mathrm{N}$ & $\mathrm{H}$ & $H d$ & $F_{S}$ \\
\hline Manus Basin (total) & 100 & 20 & 0.52 & $\mathbf{- 2 5 . 6 0}$ \\
Solwara 8 & 47 & 9 & 0.45 & $\mathbf{- 7 . 2 9}$ \\
Mound 1 & 34 & 9 & 0.46 & $\mathbf{- 8 . 1 2}$ \\
Mound 2 & 13 & 4 & 0.42 & -1.66 \\
South Su & 53 & 16 & 0.59 & $\mathbf{- 1 8 . 3 2}$ \\
Mound 3 & 10 & 3 & 0.38 & -1.16 \\
Mound 4 & 43 & 14 & 0.63 & $\mathbf{- 1 3 . 9 7}$
\end{tabular}

441

442 
443 Table 3. Summary statistics for eight microsatellite loci amplified from Bathymodiolus

444 manusensis from Manus Basin. $\mathrm{n}=$ number of individuals, $\mathrm{a}=$ number of alleles, $R s=$ allelic

445 richness, $H_{E}=$ expected heterozygosity, $H_{O}=$ observed heterozygosity (bold = significant

446 heterozygote deficiency).

447

\begin{tabular}{llrrrrrrrr}
\hline & \multicolumn{1}{c}{$B m 17$} & \multicolumn{1}{c}{$B m 22$} & \multicolumn{1}{c}{$B m 23$} & \multicolumn{1}{c}{ Bm53 } & \multicolumn{1}{c}{ Bm63 } & \multicolumn{1}{c}{ Bm76 } & \multicolumn{1}{c}{$B m 81$} & \multicolumn{2}{c}{$B m 83$} \\
\hline Solwara 8 & $\mathrm{n}$ & 140 & 137 & 126 & 133 & 91 & 136 & 129 & 142 \\
& $\mathrm{a}$ & 3 & 17 & 8 & 5 & 20 & 6 & 16 & 12 \\
& $R s$ & 3.00 & 15.74 & 6.04 & 4.66 & 13.85 & 5.70 & 14.14 & 8.75 \\
& as & $264-368$ & $236-284$ & $238-270$ & $243-264$ & $198-262$ & $189-206$ & $197-245$ & $206-224$ \\
& $H_{O}$ & 0.24 & 0.91 & 0.55 & $\mathbf{0 . 4 4}$ & 0.78 & 0.64 & 0.86 & 0.58 \\
& $H_{E}$ & 0.29 & 0.89 & 0.61 & $\mathbf{0 . 5 7}$ & 0.85 & 0.65 & 0.86 & 0.55 \\
\hline South Su & $\mathrm{n}$ & 65 & 63 & 53 & 61 & 35 & 58 & 60 & 61 \\
& $\mathrm{a}$ & 3 & 18 & 5 & 4 & 13 & 7 & 13 & 8 \\
& $R S$ & 3.00 & 18.00 & 5.00 & 4.00 & 13.00 & 7.00 & 13.00 & 8.00 \\
& $\mathrm{as}$ & $264-268$ & $228-287$ & $238-265$ & $251-264$ & $198-263$ & $189-210$ & $188-258$ & $210-223$ \\
& $H_{O}$ & 0.29 & 0.89 & 0.62 & 0.43 & 0.94 & 0.71 & 0.73 & 0.54 \\
& $H_{E}$ & 0.28 & 0.86 & 0.62 & 0.47 & 0.88 & 0.69 & 0.85 & 0.56 \\
\hline
\end{tabular}

448

449

450 
451 Table 4. Pairwise comparisons of Bathymodiolus manusensis from two mound each of two sites 452 in Manus Basin. $\mathrm{F}_{\mathrm{ST}}$ from microsatellites above the diagonal, $\varphi_{\mathrm{ST}}$ from partial $C O I$ below the 453 diagonal. No pairwise estimates of population differentiation were significant $(P<0.05)$.

454

\begin{tabular}{lcccc}
\hline & $\begin{array}{c}\text { Solwara 8 } \\
\text { Mound 1 }\end{array}$ & $\begin{array}{c}\text { Solwara 8 } \\
\text { Mound 2 }\end{array}$ & $\begin{array}{c}\text { South Su } \\
\text { Mound 3 }\end{array}$ & $\begin{array}{c}\text { South Su } \\
\text { Mound 4 }\end{array}$ \\
\hline SW8 Mound 1 & - & 0.00 & 0.00 & 0.00 \\
SW8 Mound 2 & 0.00 & - & 0.00 & 0.00 \\
SSU Mound 3 & 0.00 & 0.02 & - & 0.00 \\
SSU Mound 4 & 0.00 & 0.00 & 0.00 & - \\
\hline
\end{tabular}

455

456

457

458 
459 Figure Legends

460

461 Figure 1. Sampling locations in Manus Lau Basin. Figure adapted from one originally published 462 in Thaler et al. (Thaler et al., 2011).

463

464 Figure 2. Bathymodiolus manusensis. Statistical parsimony network for COI haplotypes from 465 samples collected at Solwara 8 and South Su, Manus Basin. Large circles represent a single 466 individual unless noted on the figure. Small black circles represent inferred haplotypes not 467 observed in this data set. Solwara 8 represented by gray circles. South Su represented by white 468 circles. Each node represents 1 base pair difference. 
471

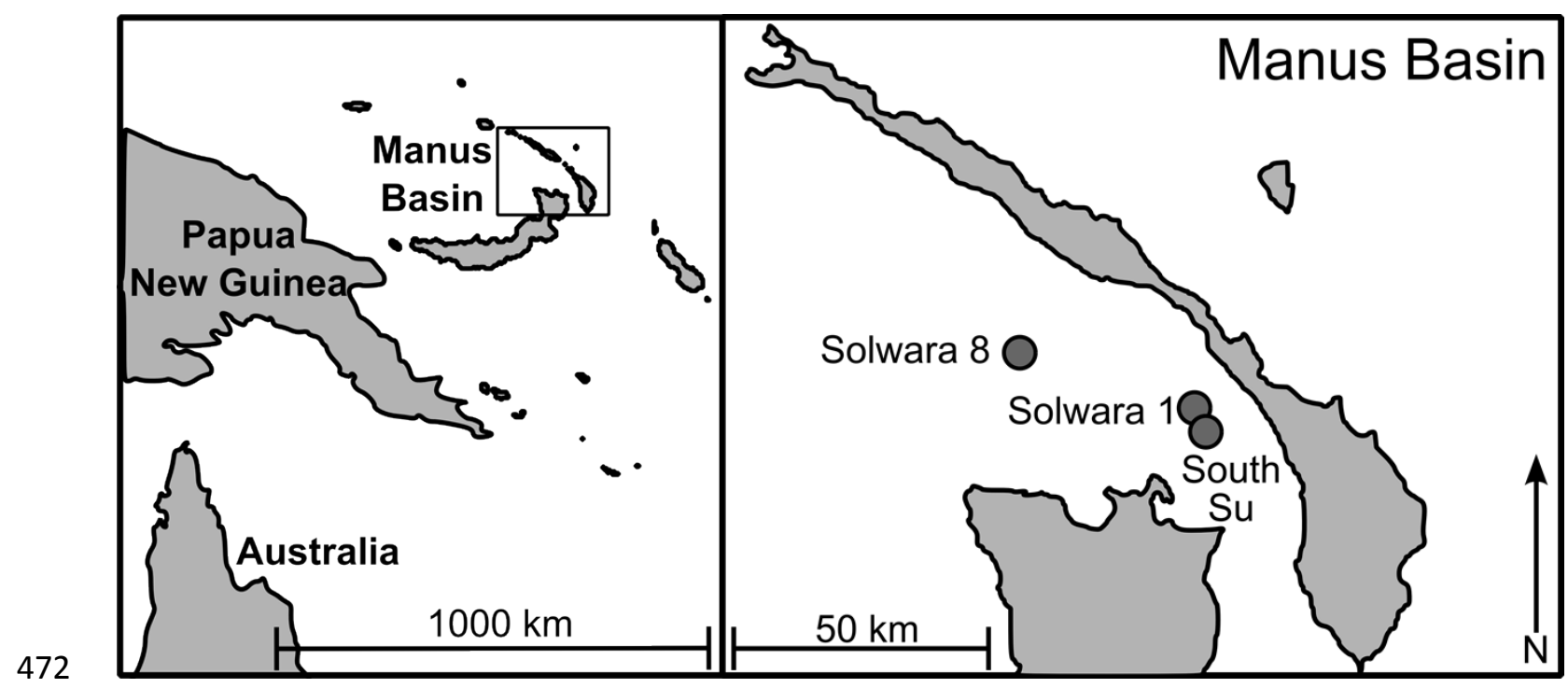

473 Figure 1. 


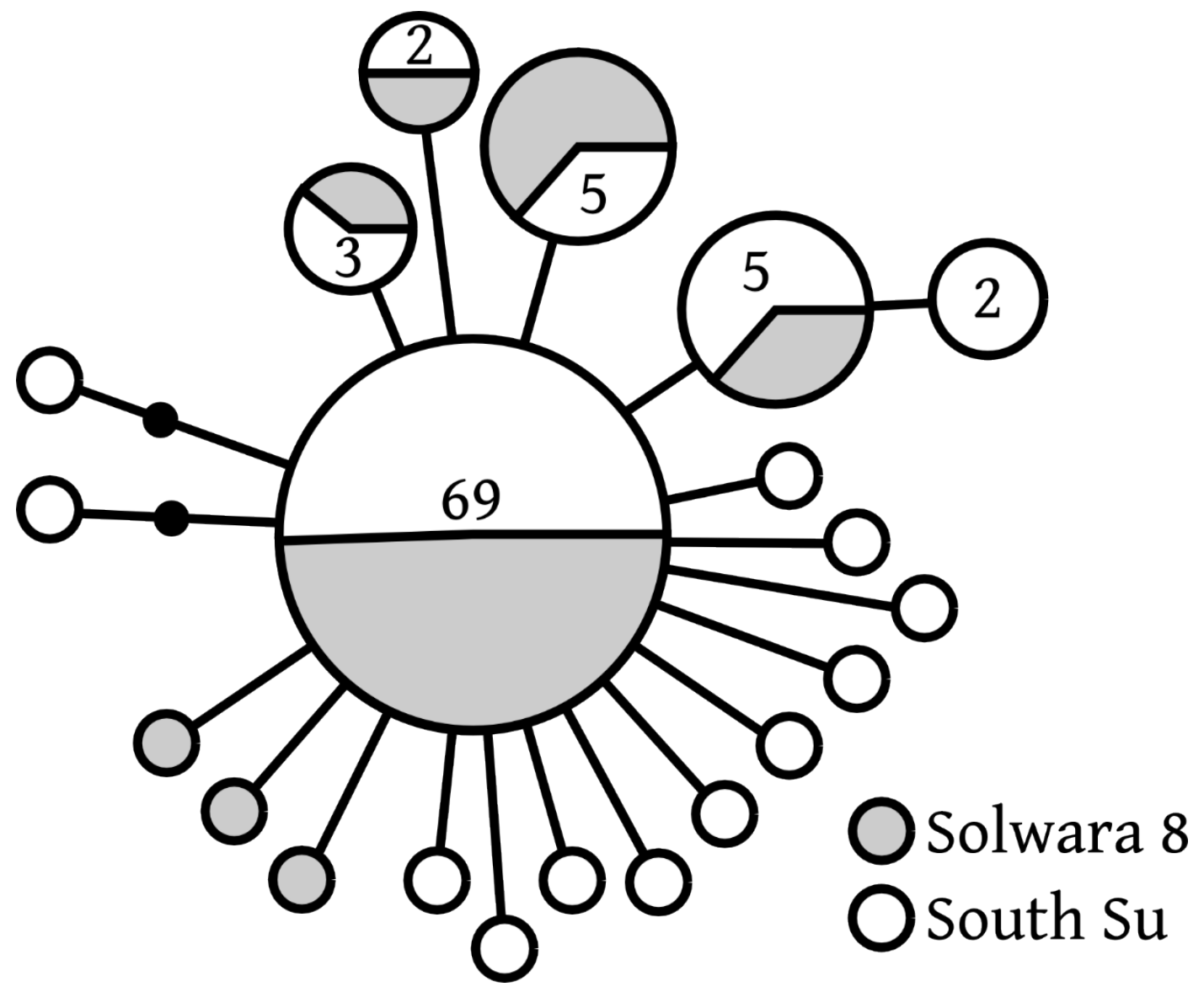

475 Figure 2.

476 